Epilepsy

\section{Epilepsy related mortality}

\section{F J K O'Callaghan, J P Osborne, C N Martyn}

\section{A decreasing problem?}

$\mathrm{T}$ he recent concept of sudden unexplained death in epilepsy (SUDEP)

has made clinicians more aware of epilepsy related deaths. With the publication of the National Sentinel Clinical Audit of Epilepsy Related Death, the general public and the media became concerned at this apparently new phenomenon. ${ }^{1}$ The impact of this audit was such that the chief medical officer, Sir Liam Donaldson, vowed "to develop an action plan to reduce the level of preventable deaths from epilepsy within three months of publication of this report". ${ }^{2}$ The Independent newspaper lamented the fact that "inadequate care by the NHS causes up to 500 deaths a year". ${ }^{3}$ The Guardian health correspondent, in an article with the headline "NHS failings blamed for deaths among epileptics", interpreted the report as saying that "about 400 people with epilepsy are dying each year because of failures in diagnosis, treatment and monitoring of the disease within the NHS". ${ }^{4}$ An editorial in The Lancet, timed to coincide with publication of the audit, concluded that "poor epilepsy management results in a substantial number of potentially avoidable deaths".

Although the increased interest in patients with epilepsy is welcome, the excited media reaction to the report, at least where it concerns children, is misleading. It should be remembered that the audit was limited by small numbers and incomplete information. Of 81 deaths that occurred in children under the age of 18 years between September 1999 and August 2002 where epilepsy was judged to be the probable cause of death from examination of the death certificate, quality of general practice and hospital based care was investigated in only 22 . It is foolhardy to make general statements about the care of children based on such small numbers and the report itself acknowledges that "an audit of epilepsy related deaths should not be assumed to be representative of the care provided to patients in general"

In any discussion of epilepsy related mortality in children, three things should be kept in mind. First, epilepsy related deaths, though tragic, are unusual. Second, data from both the UK and USA show that mortality from epilepsy is declining rather than increasing. Third, the majority of epilepsy related deaths occur in patients whose epilepsy is symptomatic of underlying neurological disease.

The time trends in epilepsy related mortality are worth examining. In both England and Wales and in the USA, there has been a steep decline in epilepsy related mortality in the paediatric population (see fig l) since $1950 .{ }^{6}$ The sorts of factors that might underlie these trends have been explored in an age-period-cohort analysis. This approach provides a way of dissecting time trends into three components-age effects, period of death effects, and birth cohort effects. Age effects describe how risk of death from disease varies by age. Period of death effects describe how mortality varies over time. They tend to be large when an effective intervention becomes available. The time trends in mortality for Hodgkin's disease, for example, show a striking period of death effect in the 1960s when successful treatment was first introduced. Birth cohort effects, on the other hand, characterise changes in mortality not by the time of death but by the time of birth. They show how experience of disease varies by generation.

When examining age effects it is clear that mortality from epilepsy shows a small peak in early life (see fig 2 ). It is possible this reflects mortality in those children with severe hypoxic ischaemic encephalopathy, brain malformations, and inherited metabolic disorders. Risk then falls to a minimum around the age of 10 years, rises again in late adolescence and early adulthood, before levelling off throughout most of adult life. There is a late peak in epilepsy related mortality in old age, presumably secondary to cerebrovascular disease. Period of death effects for epilepsy mortality are small (see fig 3). The implication here is that the introduction of new treatments for epilepsy have had little impact on mortality. By contrast, birth cohort effects in epilepsy mortality are large (see fig 4). Among both sexes in England and Wales, mortality declined strikingly in successive birth cohorts born after around 1950. This finding raises the possibility that the incidence of epilepsy is declining-a view supported by data from longitudinal studies such as the National Child Development Study and the MRC National Survey of Health and Development. ${ }^{78}$ It is also compatible with ideas that emphasise the importance of early life in the aetiology of epilepsy and in the subsequent risk of epilepsy related death.

\section{PATIENTS WITH UNDERLYING NEUROLOGICAL PROBLEMS ARE THOSE MOST AT RISK}

Three recent large studies have examined the determinants of epilepsy related mortality, two of which specifically concentrated on the paediatric population. All the studies show that the only strong risk factor for epilepsy mortality is the coexistence of an accompanying severe neurological deficit. Camfield and colleagues, in their longitudinal study of 700 children with epilepsy from Nova Scotia, concluded that unexpected death in epilepsy is rare in the absence of an underlying neurological problem. ${ }^{9}$ Callenbach and colleagues' Dutch five year follow up study of mortality risk in children with epilepsy recorded nine deaths among 472 children. All the deceased children had epilepsy that was caused by a static or progressive neurological disorder. There were no deaths among 328 children who had non-symptomatic epilepsy. They concluded that there was "no indication that children who have non-symptomatic epilepsy have an increased mortality risk compared with the general population.". ${ }^{10}$ Lhatoo and colleagues, in their prospective population based cohort study of patients with epilepsy $(n=792)$, found that the standardised mortality ratios (SMRs) for patients with epilepsy due to congenital neurological deficits, in those with acute symptomatic epilepsy and in those with remote symptomatic epilepsy were 25,3 , and 3.7 respectively, whereas the SMR for those with idiopathic epilepsy was not significantly different from unity $(1.3,95 \%$ CI 0.9 to 1.9$).{ }^{11}$

\section{THE RELATION BETWEEN THERAPY AND MORTALITY}

It is easy to understand why some may now think that poor medical care may be a major cause of epilepsy related mortality. First, witness accounts of cases of SUDEP state that death is temporally related to seizure activity. ${ }^{12}$ Second, studies have repeatedly shown that polypharmacy and poor seizure control are risk factors for SUDEP. ${ }^{13}$ 

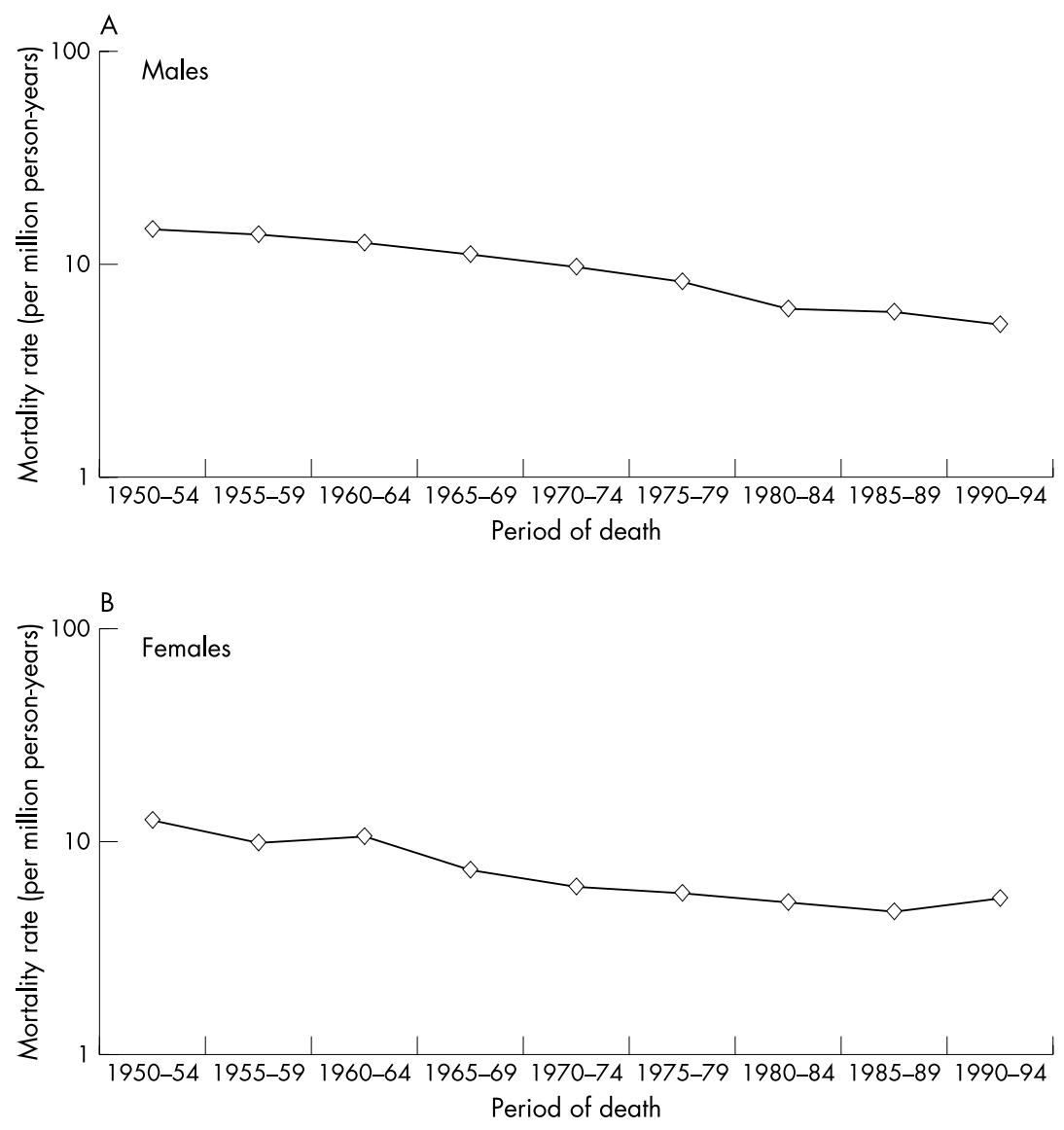

Figure 1 Epilepsy mortality rates in the paediatric population (0-19 year olds) in England and Wales 1950-94.

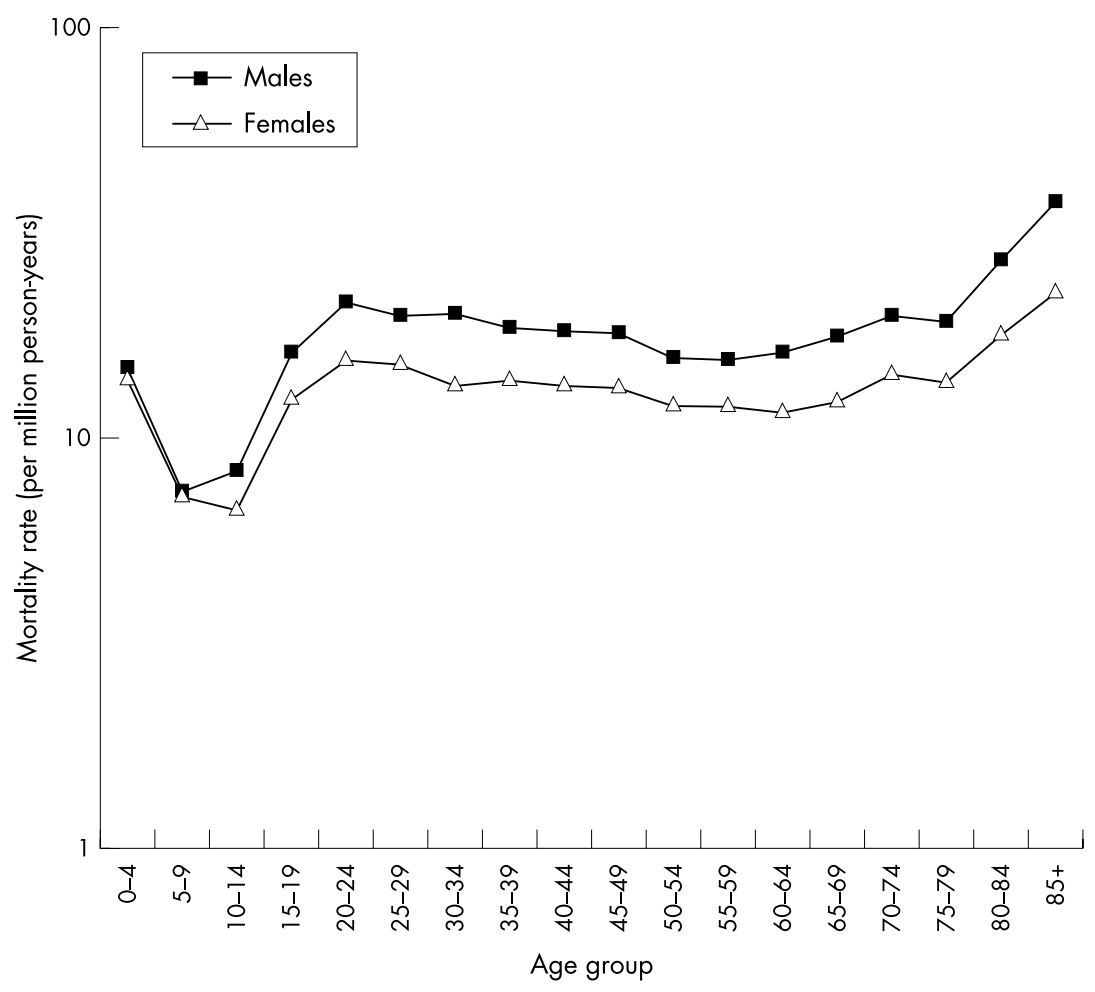

Figure 2 Epilepsy mortality rates by age group during the period 1950-94 controlling for the effects of period of death and cohort of birth.
Third, the sentinel audit highlighted inadequate care in 17 of the 22 children studied. There had been inadequate access to consultant paediatricians and, more specifically, consultant paediatric neurologists. There had been poor antiepileptic drug management and a proportion of children had not been fully investigated.

However, there is no direct evidence that there is a causal relation between therapeutic management and epilepsy related death. The lack of a period of death effect in epilepsy mortality over the past 50 years suggests that the introduction of new antiepileptic drugs has not had a large effect on reducing risk of death. The observation that the risk of SUDEP is higher in children whose seizure control is poor or who are taking multiple antiepileptic drugs may reflect the severity of the child's underlying brain disorder rather than the inadequacy of his or her care. Every paediatric neurologist or paediatrician with an interest in epilepsy will have children with uncontrolled seizures taking multiple anticonvulsants on their case-load. For the most part, epilepsy related death in children occurs in those with difficult to treat symptomatic epilepsy. It may, and does, occur in children managed well by conscientious and knowledgeable paediatricians and paediatric neurologists.

\section{CONCLUSION}

The recent interest in SUDEP and the publication of the National Sentinel Audit has brought welcome and overdue attention to patients with epilepsy. The findings-even if they are derived from only 22 deaths-suggest that care could be improved. There is a strong and urgent case for increasing the numbers of paediatric neurologists and paediatricians with an interest in epilepsy and creating efficient managed clinical networks to ensure high standard care and the best possible quality of life for patients with epilepsy. However, there is no evidence that epilepsy related mortality is an increasing problem. On the contrary, analysis of population based data shows that it has been declining since the middle of the last century and that successive generations are less likely to suffer an epilepsy related death. The children who suffer epilepsy related deaths are most often those with severe underlying neurological disorders and, unfortunately, they will sometimes die despite optimal care. It is right that we should discuss the increased risk of mortality with the families of these children with serious neurological handicap. However, we should reassure our patients who are neurologically normal that their epilepsy 


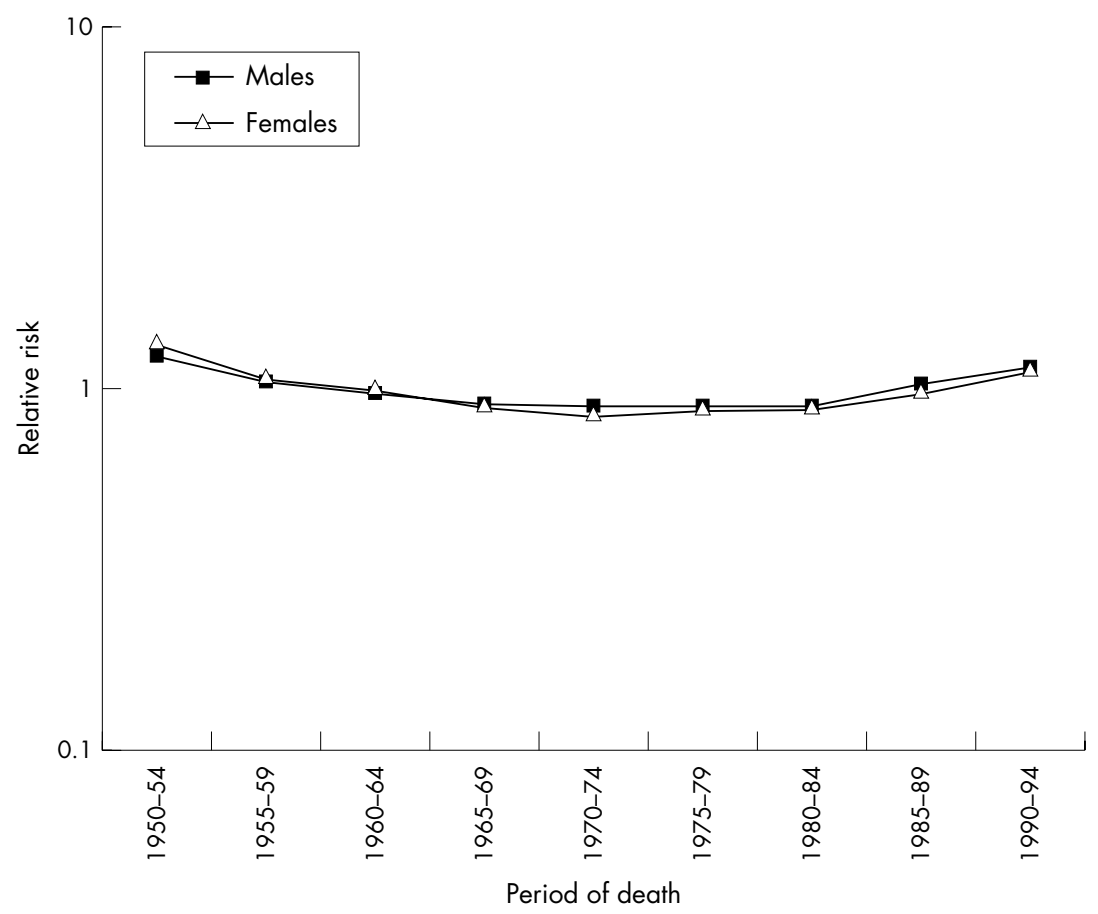

Figure 3 Epilepsy mortality rates by period of death for the period 1950-94 controlling for the effects of age and cohort of birth.

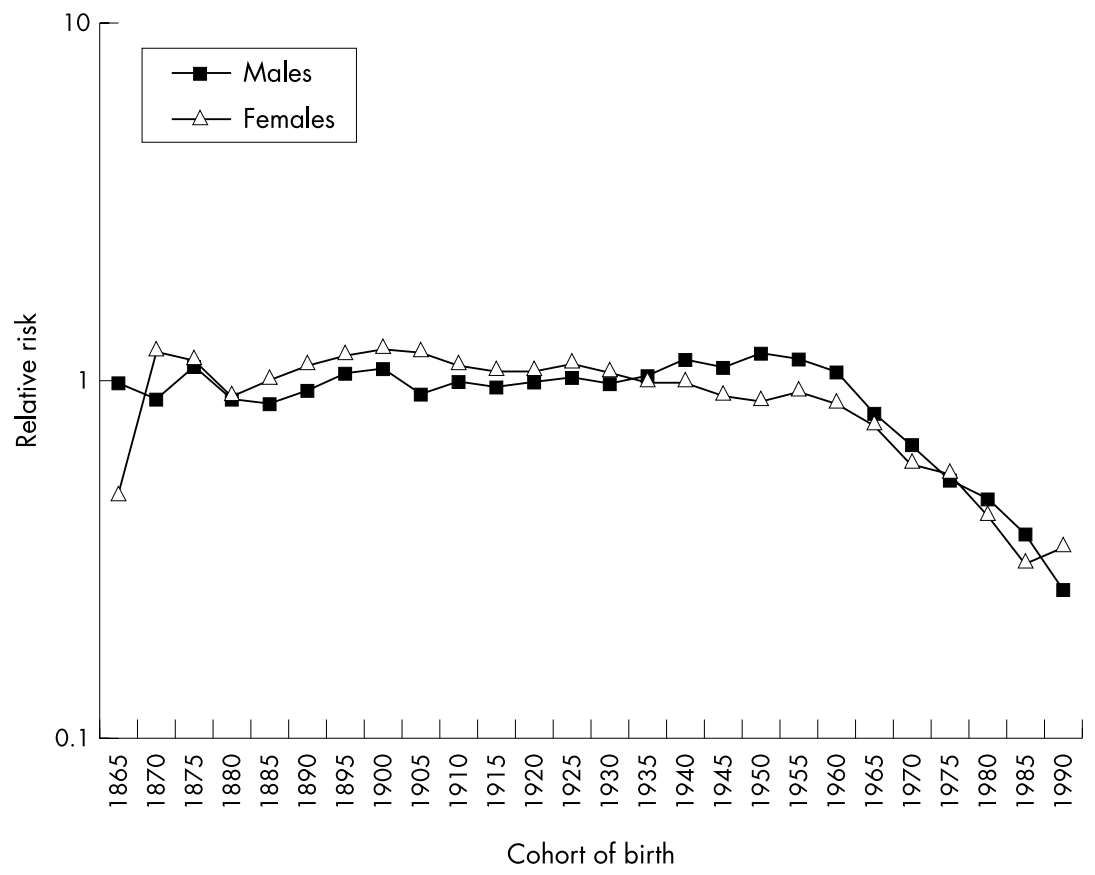

Figure 4 Epilepsy mortality rates by cohort of birth in the period 1950-94 controlling for the effects of age and period of death. is unlikely to cause their death. In the long run we might do well to pay more attention to the early life causes of symptomatic epilepsies that are the fundamental reason for most epilepsy related mortality.

Arch Dis Child 2004;89:705-707.

doi: $10.1136 /$ adc. 2003.036558

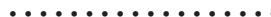

Authors' affiliations

F J K O'Callaghan, Department of Paediatric Neurology, Bristol Royal Hospital for Children, Institute of Child Health, Upper Maudlin Street, Bristol BS2 8BJ, UK

J P Osborne, Royal United Hospital, Combe Park, Bath BA1 3NG, UK

C N Martyn, MRC Environmental Epidemiology Unit, Southampton General Hospital, Tremona Road, Southampton SO16 6YD, UK

Correspondence to: Dr F J K O'Callaghan, Department of Paediatric Neurology, Bristol Royal Hospital for Children, Institute of Child Health, Upper Maudlin Street, Bristol BS2 8BJ, UK; finbar.ocallaghan@ubht.nhs.swest.uk

\section{REFERENCES}

1 Anon. National clinical audit of epilepsy-related death. National Institute of Clinical Excellence and Epilepsy Bereaved, May 2002.

2 Donaldson L. Statement from Chief Medical Officer to Epilepsy Bereaved-for the launch of National Sentinel Audit into Epilepsy-Related Death (SUDEP)

3 Duckworth L. The Independent, 21 May 2002.

4 Meikle J. The Guardian, 21 May 2002.

5 Pedley TA, Hauser WA. Sudden death in epilepsy: a wake-up call for management. Lancet 2002;359:1790-1.

6 O'Callaghan FJK, Osmond C, Martyn CN. Trends in epilepsy mortality in England and Wales and the United States, 1950-1994. Am J Epidemiol 2000; 151:182-9.

7 Britten N, Wadsworth MEJ, Fenwick PBC. Stigma in patients with early epilepsy: a national longitudinal study. J Epidemiol Community Health 1984;38:291-5.

8 Kurtz Z, Tookey P, Ross E. Epilepsy in young people: 23 year follow-up of the British national child development study. BMJ 1998;316:339-42.

9 Camfield CS, Camfield PR, Veugelers PJ. Death in children with epilepsy: a population-based study. Lancet 2002;359:1891-5.

10 Callenbach PMC, Westendorp RGJ, Geerts AT, et al. Mortality risk in children with epilepsy: the Dutch study of epilepsy in childhood. Pediatrics 2001;107:1259-63.

11 Lhatoo SD, Johnson AL, Goodridge DM, et al Mortality in epilepsy in the first 11 to 14 years after diagnosis: multivariate analysis of a longterm, prospective, population-based cohort. Ann Neurol $2001 ; 49: 336-44$.

12 Langan Y, Nashef L, Sander JWAS. Sudden unexpected death in epilepsy: a series of witnessed deaths. J Neurol Neurosurg Psychiatry 2000;68:211-13.

13 Walczak TS, Leppik IE, D'Amelio M, et al. Incidence and risk factors in sudden unexpected death in epilepsy: a prospective cohort study. Neurology 2001;56:519-25. 